\title{
Quality of nursing care and satisfaction of patients attended at a teaching hospital ${ }^{1}$
}

\author{
Juliana Santana de Freitas ${ }^{2}$ \\ Ana Elisa Bauer de Camargo Silva ${ }^{3}$ \\ Ruth Minamisava ${ }^{4}$ \\ Ana Lúcia Queiroz Bezerra ${ }^{3}$ \\ Maiana Regina Gomes de Sousa ${ }^{5}$
}

Objectives: assess the quality of nursing care, the patients' satisfaction and the correlation between both. Method: cross-sectional study, involving 275 patients hospitalized at a teaching hospital in the Central-West of Brazil. The data were collected through the simultaneous application of three instruments. Next, they were included in an electronic database and analyzed in function of the positivity, median value and Spearman's correlation coefficients. Results: among the nursing care assessed, only two were considered safe - hygiene and physical comfort; nutrition and hydration - while the remainder were classified as poor. Nevertheless, the patients were satisfied with the care received in the domains assessed: technical-professional, confidence and educational. This can be justified by the weak to moderate correlation that was observed among these variables. Conclusion: Despite the quality deficit, the patients' satisfaction level with the nursing care received was high. These results indicate that the institution needs to center its objectives on a continuing evaluation system of the care quality, aiming to attend to the patients' expectations.

Descriptors: Nursing Care; Quality of Health Care; Patient Satisfaction; Patient Safety.

\footnotetext{
${ }_{1}$ Paper extracted from master's thesis "Evaluation of the quality of nursing care and patient satisfaction in a teaching hospital in the Midwest region of Brazil", presented to Faculdade de Enfermagem, Universidade Federal de Goiás, Goiânia, GO, Brazil. Supported by Conselho Nacional de Desenvolvimento Científico e Tecnológico (CNPq), process \# 135048/2011-7.

$2 \mathrm{MSc}, \mathrm{RN}$

${ }^{3} \mathrm{PhD}$, Adjunct Professor, Faculdade de Enfermagem, Universidade Federal de Goiás, Goiânia, GO, Brazil.

${ }^{4} \mathrm{PhD}$, Associate Professor, Faculdade de Enfermagem, Universidade Federal de Goiás, Goiânia, GO, Brazil.

${ }^{5}$ Master's student, Faculdade de Enfermagem, Universidade Federal de Goiás, Goiânia, GO, Brasil.
}

Corresponding Author:

Juliana Santana de Freitas

Rua 240, 157, Casa 02

Setor Leste Universitário

CEP: 74.605-170, Goiânia, GO, Brasil

E-mail: juzinha_gyn@hotmail.com
Copyright ( 2014 Revista Latino-Americana de Enfermagem This is an Open Access article distributed under the terms of the Creative Commons Attribution Non-Commercial License (CC BY-NC).

This license lets others distribute, remix, tweak, and build upon your work non-commercially, and although their new works must also acknowledge you and be non-commercial, they don't have to license their derivative works on the same terms. 


\section{Introduction}

In the globalized context, in which science, technology and information lie within many people's reach, the professions, and particularly nursing, are confronted with the need to improve their work processes with a view to guaranteeing high-quality care provision to the patients ${ }^{(1)}$

The new health care technologies have increased the costs of the health sector and the population's expectations with regard to the services offered. Nevertheless, studies indicate flaws in the quality and safety of care, involving unwanted events that negatively affect the health organizations' image ${ }^{(2-4)}$.

Although different countries present problems in the quality and safety of hospital care, efforts have been made to improve their efficiency and efficacy ${ }^{(5-6)}$. Therefore, the World Health Organization ${ }^{(7)}$ has recommended managers to take into account the citizens' expectations in decision making and, since then, various studies about patient satisfaction have been conducted(8-10). Patient satisfaction is not only important by itself, it has also been suggested as a care quality indicator in developed countries ${ }^{(11)}$

Nursing is aware of its responsibility for the quality of its care provision to the patients, the institution, ethics, laws and professional standards, as well as of how its performance contributes to the valuation of care and the patients' satisfaction(12).

In that sense, listening to what the patients have to say about the care they receive and about their satisfaction can be a chance to construct an outcome indicator, which provides the managers with some courses to decide on transformations and innovations. As a result of changes in the global context, patients and their relatives have required a renewed commitment to qualitative improvements in health service organizations, stimulated by patient safety concerns ${ }^{(13)}$.

The health institutions have adopted the assessment of patient safety as a strategy to obtain a set of perceptions related to the quality of the care received, providing information that benefits the organization of these services ${ }^{(10)}$

In recent years, many studies have been developed to get to know how hospitalized patients perceive the care received ${ }^{(8-10 ; 14)}$. Nevertheless, few studies demonstrate the relation between the quality of nursing care and the patients' satisfaction.

In that sense, this study was aimed at: assessing the quality of the care the nursing team provides according to the patients' perspective; assess the patients' satisfaction with the nursing care they receive and check the relation between nursing care quality and patient satisfaction.

\section{Methods}

Cross-sectional study, involving 275 patients hospitalized at the Medical Clinic, Orthopedic Clinic, Plastic Surgery and Tropical Clinic of a teaching hospital in the Central-West of Brazil. The inclusion criteria were: age 18 years or older; being hospitalized for more than 48 hours and being in favorable clinical conditions to answer the data collection instruments. Eligible patients who accepted the invitation to participate were asked to sign the Informed Consent Form (ICF).

The data were collected between November 2012 and January 2013 through interviews with the patients, using three instruments that were simultaneously applied.

The first contained questions to identify the population's sociodemographic characteristics.

The second instrument used, called "Interview Script on Nursing Care for Hospitalized Patients"(15), was aimed at assessing the quality of nursing care delivery. It was constructed based on the Theory of Basic Human Needs $(\mathrm{BHN})^{(16)}$, organized in nine items and 40 subitems according to the affected need, and validated at the Regional University Hospital of Northern Paraná. For all the sub-items, three alternative answers existed yes, no and does not apply, only one of which could be chosen ${ }^{(15)}$

The data obtained from the interviews held with the help of this script were included in a Microsoft Excel 2010 electronic worksheet, specifically elaborated for this purpose. Initially, the positivity of the replies was calculated in percentage form. Based on the calculation of the positivity, the items and sub-items were classified ${ }^{(17)}$. Only items and sub-items with positivity levels of $80 \%$ or higher were considered good in this study.

The third instrument used was the Brazilian version of the Patient Satisfaction Instrument(18), called "Instrumento de Satisfação do Paciente" (ISP)(8), which aims to discover the patients' satisfaction with the nursing care they receive.

The ISP consists of 25 assertions, grouped in three domains: technical-professional, confidence and educational, constructed in the form of five-point Likert scale: I completely agree, I agree, no opinion, I disagree and I completely disagree ${ }^{(8)}$. To analyze 
the internal consistency of the ISP, Cronbach's Alpha coefficient was used.

The data from the interviews using the ISP were included in Microsoft Excel 2010 electronic worksheets, used to score the scale. The median answer score for each instrument item was calculated, considering scores of four or higher $(\geq 4)$ as satisfied in this study.

Spearman's correlation coefficients were used to describe the correlations between the quality of the nursing care and the patients' satisfaction.

The statistical analysis was developed in the Statistical Package for the Social Sciences (SPSS) software, version 19.0 for Windows. The significance level was set at 0.05 .

This research received approval from the Ethics Committee in Human and Animal Research at the Hospital das Clínicas of Universidade Federal de Goiás under protocol No. 064/2008 and complied with the premises of National Health Council Resolution 196/96(19).

\section{Results}

The analysis of the interviewees' sociodemographic profile revealed that the ages ranged between 18 and 79 years, with a median of 48 years and $41-50$ years as the most frequent age range.

Among the 275 interviewees, 194 (70.5\%) were married or living with their partner; 169 (61.5\%) were male; 155 (56.4\%) were employed and 154 (56.0\%) studied for nine years or more.

The data collected through the Interview Script on Nursing Care for Hospitalized Patients permitted assessing the quality of nursing care. Figure 1 displays the classification of nursing care and the numerical synthesis of the results obtained in the interviews with the patients.

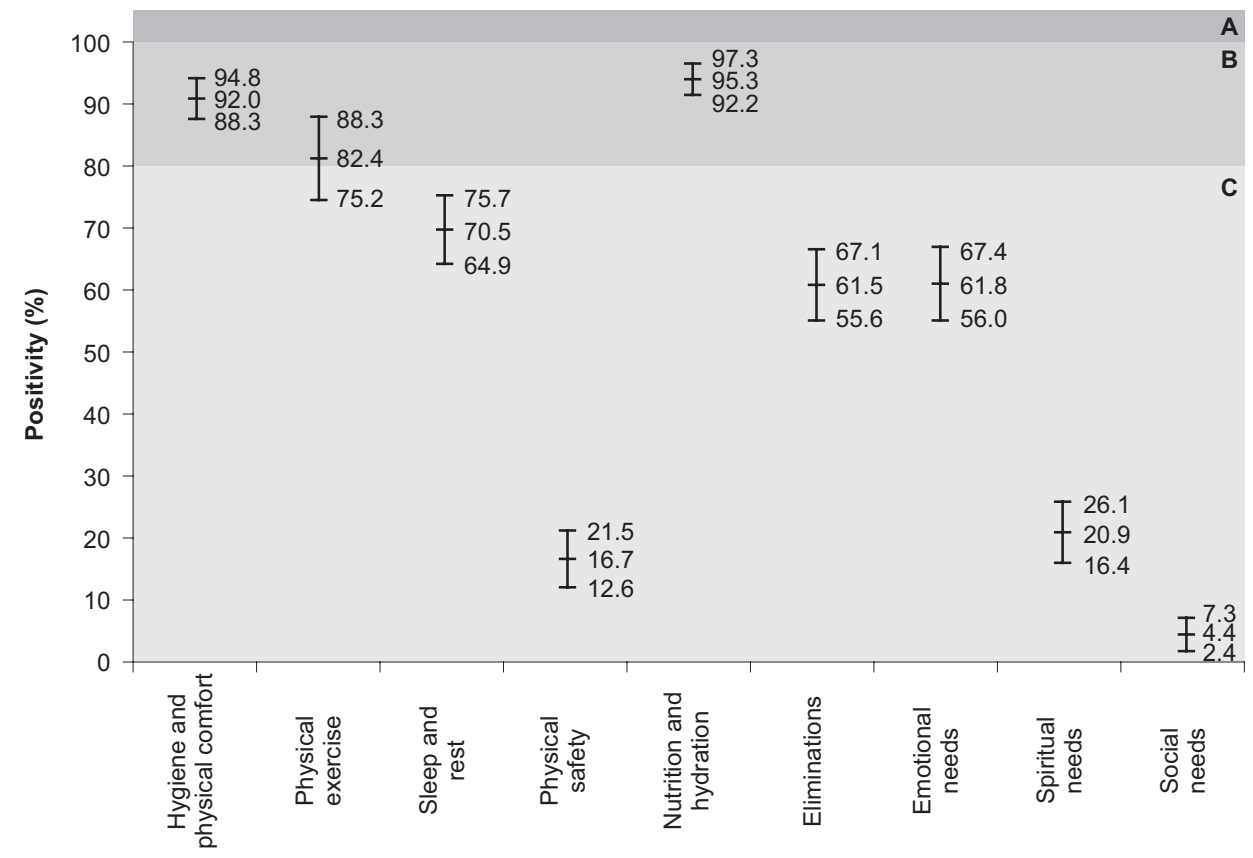

A: Desirable care (100\% de positivity); B: Safe care (80 to $99 \%$ positivity); C: Poor care (below $80 \%$ of positivity)

Figure 1 - Distribution of nursing care quality assessment items according to positivity and confidence interval. Goiânia, GO, Brazil, 2013

It is highlighted that none of the nine items assessed reached the desirable level of nursing care (100\% positivity), while two were considered safe and high-quality (positivity of $80 \%$ or higher) and the remainder were seen as poor, mainly those focused on spiritual needs, physical safety and social needs, with the lowest positivity scores.
To understand the patient's satisfaction with the nursing care, the Patient Satisfaction Instrument was used. Its internal consistency was assessed with the help of Cronbach's Alpha coefficient, which was considered acceptable for the technical-professional $(\alpha=0.709)$ and educational $(\alpha=0.750)$ domains and good for the confidence domain $(\alpha=0.834)$. 
Next, the distribution of the median values of the patients' scores and the interquartile interval (IQI) are displayed for each ISP item (Table 1).

The predominance of the median scores 4 and 5 (92\%) was observed in all domains. This indicates the patients' high level of satisfaction with the nursing care assessed.

To check for the interrelation between the quality of nursing care and the patients' satisfaction, Spearman's correlation coefficient was calculated (Table 2).

Table 1 - Distribution of the median score and interquartile interval of the patients' answers for each domain of the Patient Satisfaction Instrument. Goiânia, GO, Brazil, 2013

\begin{tabular}{|c|c|c|}
\hline Patients' Answers per Domain & Median & $\begin{array}{l}\text { Interquartile } \\
\text { Interval (IQI) }\end{array}$ \\
\hline \multicolumn{3}{|l|}{ Technical-professional domain } \\
\hline The nursing team professionals are keen to show me how to follow the medical orientations & 4 & $2-5$ \\
\hline The nursing team professionals are always too disorganized to seem calm* & 5 & $4-5$ \\
\hline The nursing team professionals give good advice & 5 & 4-5 \\
\hline The nursing team professionals really know what they are talking about & 5 & $4-5$ \\
\hline The nursing team professionals are very slow to do things for $\mathrm{me}^{*}$ & 5 & $4-5$ \\
\hline The nursing team professionals do not do their job correctly* & 5 & $4-5$ \\
\hline The nursing team professionals are skilled in helping the doctor with the procedures & 5 & $4-5$ \\
\hline \multicolumn{3}{|l|}{ Confidence Domain } \\
\hline The nursing team professionals should be more thoughtful than they are* & 4 & $2-5$ \\
\hline The nursing team professionals are pleasant to be with & 5 & $5-5$ \\
\hline We feel at ease to ask the nursing team professionals questions & 5 & $4-5$ \\
\hline The nursing team professionals should be friendlier than they are* & 4 & $2-5$ \\
\hline The nursing team professionals are able to understand how I feel & 5 & $4-5$ \\
\hline When I need to talk to someone, I can tell my problems to the nursing team professionals & 5 & $4-5$ \\
\hline The nursing team professionals are too busy at the infirmary to lose time talking to me* & 5 & $3-5$ \\
\hline The nursing team professionals are understanding when listening to the patient's problems & 5 & $4-5$ \\
\hline The nursing team professionals are not patient enough* & 5 & $4-5$ \\
\hline I am tired of the nursing team professionals talking to me as if I were an inferior person* & 5 & $5-5$ \\
\hline I already feel better just by talking to the nursing team professionals & 5 & $4-5$ \\
\hline \multicolumn{3}{|l|}{ Educational Domain } \\
\hline $\begin{array}{l}\text { The nursing team professionals often think that you are unable to understand the medical explanation about the } \\
\text { disease, so they simply don't bother explaining }{ }^{*}\end{array}$ & 5 & $3-5$ \\
\hline The nursing team professionals explain things in simple language & 5 & $4-5$ \\
\hline The nursing team professionals ask a lot of questions but, when they receive the answer, they seem not to bother* & 5 & $4-5$ \\
\hline I would like the nursing team professionals to give me further information about my test results* & 2 & $1-4$ \\
\hline It is always easy to understand what the nursing team professionals are saying & 5 & $4-5$ \\
\hline The nursing team professionals provide the orientations at the correct speed & 4 & $4-5$ \\
\hline The nursing team professionals always provide complete and sufficient explanations about why the tests were requested & 2 & $2-4$ \\
\hline
\end{tabular}

*The attribute of this question is negative and, therefore, its scores were inverted

Table 2 - Spearman's Correlation Coefficient (P-value) between the nine assessment items of the nursing care quality and the three domains of the Patient Satisfaction Instrument. Goiânia, GO, Brazil, 2013

\begin{tabular}{lcc}
\hline \multicolumn{1}{c}{ Assessment Items of Nursing Care Quality } & \multicolumn{2}{c}{ Domains of the Patient Satisfaction Instrument } \\
\cline { 2 - 3 } Hygiene and Physical Comfort & Technical-professional & Confidence \\
Physical Exercise & $0.373(0.000)$ & $0.275(0.000)$ \\
Sleep and Rest & $0.456(0.000)$ & $0.336(0.000)$ \\
Physical Safety & $0.435(0.000)$ & $0.468(0.000)$ \\
Nutrition and Hydration & $0.195(0.001)$ & $0.298(0.000)$ \\
Eliminations & $0.083(0.169)$ & $0.106(0.080)$ \\
Emotional Needs & $-0.037(0.544)$ & $0.012(0.837)$ \\
Spiritual Needs & $0.521(0.000)$ & $0.434(0.000)$ \\
Social Needs & $0.293(0.000)$ & $0.000)$ \\
\hline
\end{tabular}


According to Table 2, in the correlation analysis of the variables, the majority revealed a significant $(p<0.05)$ weak $(r<0.03)$ to moderate $(0.03<r<0.5)$ correlation, particularly the emotional needs, which were related to all other domains of satisfaction.

\section{Discussion}

In this study, the quality of nursing care and the patient's satisfaction with that care were investigated. The findings revealed that none of the nursing care reached the desirable level and that only two were considered safe - hygiene and physical comfort and nutrition and hydration - both belonging to the psychobiological BHN. This conclusion shows that nursing faces difficulties to broaden the range of its care, so as to include the patients' emotional and psychospiritual needs.

In care delivery to people with health problems, nursing should focus its actions on the biological, social, spiritual and mental demands of human beings. In order to stimulate and help people to satisfy their spiritual needs, nursing professionals can use some interventions, such as: offering support to spiritual or religious needs, facilitation of religious practice, spiritual counseling, hiring of a spiritual advisor and support in the solution between treatment and spiritual beliefs( ${ }^{(20)}$.

Another concerning result was the poor classification of the physical safety item. Unsafe health care results in considerable avoidable morbidity and mortality rates and additional spending on the maintenance of health systems and represent a great concern nowadays(2).

Safety is an important dimension of quality, defined as people's right to have "the risk of unnecessary healthcare-related damage reduced to an acceptable minimum"(21).

As regards the social needs, it was verified that the nursing team hardly values these aspects. The social needs comprise different $\mathrm{BHN}$ that are affected during hospitalizations, including: self-esteem, self-image, attention, acceptance, gregarious behavior, recreation and leisure ${ }^{(16)}$.

A study highlights that hospitalized patients demand a more comprehensive intervention level from health professionals, involving mental as well as social aspects, with a view to minimizing unnecessary mental health risks, such as stress ${ }^{(22)}$.

Therefore, nursing care should be delivered in a humane and holistic manner and in the light of an integrated approach, without excluding emotional, more comprehensive and personalized care to its clients, with a view to high-quality care(23).

The excessive valuation of the psychobiological needs, to the detriment of other needs, may be associated with the reality most of the nursing professionals experiences, who are confronted with overcrowded hospitals, limited resources, lack of professionals, an excessive work burden and multiple task demands each day, without being able to provide all the nursing care.

The omission of nursing care can also be linked with the lack of or deficient organization and planning of managerial and scientific care demands. In this context, the systemization of nursing care (SNC) is an instrument capable of guiding the nursing professionals in the technical and scientifically conscious and competent execution of care.

In the evaluation of patient satisfaction, a high level of satisfaction with the assessed nursing care was observed, as observed by the predominance of median scores 4 and 5 (92\%) in all domains.

Some phrases showed a concentration of answers at higher levels, leading to high median scores, but with comprehensive interquartile intervals. This interval indicates the variability of the answers and, consequently, of the patients' opinion who, despite being part of the same context, have their own quality concepts, based on their culture, values and experiences.

These findings support the results of a study on patients' satisfaction with nursing care at two hospitals in São Paulo, using the $\operatorname{ISP}^{(8)}$. Studies undertaken at a rooming-in unit and gastroenterology service of a teaching hospital from the interior of the State of São Paulo also identified a high level of patient satisfaction with all items and domains of the instrument ${ }^{(9,14)}$.

Also regarding the patient satisfaction results, two phrases in the educational domain stood out negatively (median 2) in comparison with the others. The first affirms that the patient would like the nursing team professionals to provide more information about the test results. The second affirms that the nursing team professionals always provide complete and sufficient explanations for why the tests were requested. This shortage in the nursing teams' educative role demonstrates that these professionals do not attend to one of the patient rights ${ }^{(24)}$.

In providing patient education activities, nursing enhances the patients' participation in their own care, a practice that is frequently discussed and encouraged nowadays ${ }^{(13)}$. The patient's satisfaction with the 
educational information by itself represents a nursing care quality indicator(25).

Concerning the interrelation between the quality of nursing care and patient satisfaction, in the correlation analysis of the variables, the majority showed a significant $(p<0.05)$ weak $(r<0.03)$ to moderate $(0.03<r<0.5)$ correlation.

The identification of a weak to moderate correlation between nursing care quality and patient satisfaction arouses questions about the existence of the gratitude bias, a feeling some patients may experience when they get care, leaving possible problems to the background(26).

As a result of health service access difficulties, patients may consider it highly satisfactory. The users may still need to recognize the use of health services as a right and, as such, independently of how they assess the service, they will continue receiving care. The patients need to put themselves in a critical and participatory situation towards the institution and not as if they were receiving a favor ${ }^{(27)}$.

All of the factors cited above may be based on the fact that the hospital users belong to a low socioeconomic and education level, ignoring basic principles of health service quality that need to be complied with and, therefore, expect less from the service and do not know what to require.

In the analysis between the assessment of nursing care quality and satisfaction, the emotional needs were correlated with all of the satisfaction domains. The relation between the nursing professional and the patient is essential to achieve positive results and satisfaction with care and represents an antecedent to feel safe ${ }^{(28)}$.

\section{Conclusion}

The assessment of nursing care quality and patient satisfaction permitted the identification of strengths and weaknesses in the study area, providing support for the reorganization of care, management and teaching activities.

Concerning the quality of the care provided by the nursing team according to the patient's perspective, it could be concluded that the nursing care delivered at the institution is deficient and that the patients are highly satisfied with the nursing care they receive in all the domains assessed. Nevertheless, a weak to moderate correlation was identified between the nursing care quality and the patients' satisfaction.

The study limitations include the use of an instrument elaborated in different health system and client contexts, which may have influenced the results found. As for the ISP, developed in the United States of America, with nursing team categories and tasks that differ from the Brazilian, its structure needed modification, replacing the term "The nurse" by "the nursing team professionals". In addition, it is highlighted that this study was developed at a single hospital. Therefore, further research is needed to confirm the results regarding the weak correlation between nursing care quality and patient satisfaction.

The study indicated that high-quality nursing services demand interventions based on scientific studies, for the purpose of care management, using the following: the establishment of indicators that permit outcome assessment; the commitment and involvement of all stakeholders in the continuous improvement process; investment in personnel development and team work; socialization of information; encouragement of innovation and creativity and, in addition, compliance with the expectations of workers and patients.

\section{References}

1. Vituri DW, Matsuda LM. Validação de conteúdo de indicadores de qualidade para avaliação do cuidado de enfermagem. Rev Esc Enferm USP. 2009;43(2):429-37.

2. World Health Organization. World Alliance for Patient Safety. Summary of the evidence on patient safety: implications for research. The Research Priority Setting Working Group of the World Alliance for Patient Safety. Geneva: World Health Organization; 2008.

3. Wachter RM, Pronovost, Shekelle P. Strategies to Improve Patient Safety: The Evidence Base Matures. Ann Intern Med. 2013;158(5 Part 1):350-2.

4. Silva AEBC, Reis AMM, Miasso AI, Santos JO, Cassiani SHB. Eventos adversos a medicamentos em um hospital sentinela do Estado de Goiás, Brasil. Rev. Latino-Am. Enfermagem. 2011;19(2):378-86.

5. Rechel B, Wright S, Edwards N, Dowdeswell B, McKee $M$. Investing in hospitals of the future. Copenhagen $\varnothing$, Denmark: European Observatory on Health Systems and Policies; 2009.

6. Aiken LH ,Sermeus W ,Van den Heede K ,Sloane DM ,Busse $R$,McKee $M$, et al. Patient safety, satisfaction, and quality of hospital care: cross sectional surveys of nurses and patients in 12 countries in Europe and the United States. BMJ. 2012;344:e1717.

7. World Health Organization. The world health report 2000. Health systems: improving performance. Geneve: WHO; 2000. 
8. Oliveira AML, Guirardello EB. Satisfação do paciente com os cuidados de enfermagem: comparação entre dois hospitais. Rev Esc Enferm USP. 2006;40(1):71-7.

9. Dorigan G, Guirardello EB. Satisfação do paciente em uma unidade de gastroenterologia. Acta Paul Enferm. 2010;23(4):500-5.

10. Lyu H, Wick EC, Housman M, Freischlag JA, Makary MA. Patient Satisfaction as a Possible Indicator of Quality Surgical Care. JAMA Surg. 2013;148(4):362-7.

11. Laschinger HS, McGillis-Hall L, Almost J. A psychometric analysis of the patient satisfaction with nursing care quality questionnaire. J Nurs Care Qual. $2004 ; 20(5): 220-30$.

12. Regis LFLV, Porto IS. Necessidades humanas básicas dos profissionais de enfermagem: situações de (in)satisfação no trabalho. Rev Esc Enferm USP. 2011;45(2):334-41.

13. World Health Organization [Internet]. Geneva Patients for patient safety. [acesso 30 mar 2013]. Disponível em: http://www.who.int/patientsafety/ patients_for_patient/en/

14. Odinino NG, Guirardello EB. Satisfação da puérpera com os cuidados de enfermagem recebidos em um alojamento conjunto. Texto Contexto Enferm. 2010;19(4):682-90.

15. Haddad MCL, Évora YDM. Qualidade da assistência de enfermagem: a opinião do paciente internado em hospital universitário público. Cienc Cuid Saúde. 2008;7(Suplem. 1):45-52.

16. Horta WA. Processo de enfermagem. São Paulo: EDUSP; 1979.

17. Carter JH. Standards of nursing care: a guide for evaluation. 2nd.ed. Nova York: Springer Pub; 1976.

18. Hinshaw AS, Atwood JR. A patient satisfaction instrument: precision by replication. Nurs Res. 1982;31:170-97.

19. Ministério da Saúde. Conselho Nacional de Saúde. Resolução 196/96. Pesquisas com seres humanos. Brasília: Ministério da Saúde; 1996. p. 26.

20. Tannure MC, Pinheiro AM. Sistematização da assistência de enfermagem. 2nd.ed. Rio de Janeiro: Guanabara Koogan; 2010.

21. Runciman $W$, Hibbert $P$, Thomson $R$, Van Der Schaaf $T$, Sherman $H$, Lewalle $P$. Towards an International Classification for Patient Safety: key concepts and terms. Int J Qual Health Care. 2009;21:18-26.

22. Lipp MEN, Frare A, Santos FU. Efeitos de variáveis psicológicas na reatividade cardiovascular em momentos de stress emocional. Estud Psicol. 2007; 24(2):161-7.
23. Morais GSN, Costa SFG, Fontes WD, Carneiro AD. Comunicação como instrumento básico no cuidar humanizado em enfermagem ao paciente hospitalizado. Acta Paul Enferm. 2009;22(3):323-7.

24. Ministério da Saúde. Carta dos direitos dos usuários da saúde. 2nd.ed. Brasília: Ministério da Saúde; 2007.

25. ANA - American Nurses Association [Internet]. Washington [acesso 30 mar 2013]. ANA Indicator History. Disponível em: http://www.nursingworld.org/ MainMenuCategories/ThePracticeofProfessionalNursing/ PatientSafetyQuality/Research-Measurement/TheNational-Database/Nursing-Sensitive-Indicators_1/ ANA-Indicator-History

26. Hollanda E, Siqueira SAV, Andrade GRB, Molinaro A, Vaitsman J. Satisfação e responsividade em serviços de atenção à saúde da Fundação Oswaldo Cruz. Ciênc Saúde Coletiva. 2012;17(12):3343-52.

27. Paiva SMA, Gomes ELR. Hospital care: assessment of users' satisfaction during hospital stay. Rev. LatinoAm. Enfermagem. 2007;15(5):973-9.

28. Mollon D. Feeling safe during an inpatient hospitalization: a concept analysis. J Adv Nurs. 2014.

Doi: $10.1111 /$ jan. 12348 